\title{
INDUCTIVE JUSTIFICATION AND DISCOVERY. ON HANS REICHENBACH'S FOUNDATION OF THE AUTONOMY OF THE PHILOSOPHY OF SCIENCE
}

Hans Reichenbach's distinction between a context of discovery and a context of justification continues to be relevant all the way up to the present. This can be seen clearly in the tense relationship between the history and the philosophy of science. In the current debates about the relationships between these two disciplines one encounters arguments that Reichenbach used to defend this distinction, as well as arguments brought forth by his critics. ${ }^{1}$ Sometimes the discussions even refer directly to the influence of Reichenbach's distinction (Giere 1999, pp. 11-18 and 217-230).

Historically, this influence can be understood to have gone hand in hand with the significance of logical empiricism in the twentieth century for the development of philosophy of science and science studies, i.e., history, sociology and psychology of science. Reichenbach used the distinction in 1938 in his "Experience and Prediction", which played a key role in the new beginning of logical empiricism in the US. Among the many motives that might have led Reichenbach to formulate this distinction, his intention to contribute to the foundation of the autonomy of a "scientific philosophy" presumably had central importance. ${ }^{2}$ In this context, its function was to clarify Reichenbach's stance towards other philosophical trends, to prove the homogeneity of the methodology and content of philosophy of science, and to distance philosophy of science from rival disciplines. Reichenbach's remarks suggest--and I shall return to this point-that "context of discovery" means above all a part of the research conducted in the natural sciences. One of the messages that Reichenbach wanted to communicate with his distinction was: the "scientific philosophy" of logical empiricism can provide a justification for the theories brought forth in the natural sciences, whereas the natural sciences themselves are not in a position to do so.

Since the "historical turn" accompanying Thomas S. Kuhn's "The Structure of Scientific Revolutions", the distinction of contexts has been increasingly influential in distinguishing among the philosophy of science and the disciplines of science studiesin particular to the relationship between the philosophy and the history of science. To put it simply, from the perspective of analytical philosophy of science-into which the tradition of logical empiricism passed over-the historical presentation of the natural sciences now stands alongside the natural sciences, which are themselves the province of the context of discovery.

I do not want to go into the details of the debates about the justification of disciplinary boundaries and relationships between the history and the philosophy of science. Rather, I would like to assume that Reichenbach's distinction lives on, and 
to seek arguments in his texts that would justify their relevance in this field. The persuasive force of these arguments transcends the contingent circumstances apart from which their genesis and local transmission cannot be made understandable.

These arguments have not yet been sufficiently acknowledged in the expansive secondary literature dealing with the context distinction-which might not be a small matter, considering their current influence. My thesis is that, for Reichenbach, the context distinction unfolds its relevance for the formation of disciplines in relation to the theory of induction. This connection has until now only seldom been mentioned. ${ }^{3}$ This is all the more astounding considering that most of the few passages where Reichenbach employed the distinction subsequent to1935 make direct reference to induction (Reichenbach 1935a, pp. 172-173; Reichenbach 1938, pp. 6-7 and 381382; Reichenbach 1944, p. 80; Reichenbach 1947, p. 2; Reichenbach 1949a, pp. 433434; Reichenbach 1949b, pp. 291-293; Reichenbach 1951, p. 231). Since induction plays a key role for Reichenbach in the natural sciences as well in epistemology, he is confronted with the question of the autonomy of epistemology. How does the application of and the thinking about induction differ between epistemology and the natural sciences? Are the differences gradual or categorical in nature?

Reichenbach's conclusive answer goes back to the pragmatic justification of induction that he developed in 1933. This justification emphasizes the normative character of epistemology in contrast to the disciplines that study science in a more descriptive manner. I am not interested in attempting a new defence of this justification-which is still controversial today - but in highlighting its role in establishing a discipline's specific claim to rationality. ${ }^{4}$ The plausible elements of this function come to light if one looks beyond Reichenbach's exaggerated fixation on logical analysis. They provide positive points of reference that can be used today in understanding the relationship between the philosophy and the history of science.

My presentation of the connection between the context distinction and induction takes into account only the version of the distinction-among the many in Reichenbach's work (Schiemann 2003; Hoyningen-Huene, this volume)-that relates to its function of contributing to the distinction between the tasks and practices of epistemology and those of other disciplines-which is probably its historically relevant function. ${ }^{5}$ I can only mention here that this version-as well as the others-goes back to a traditional distinction between genesis and validity that reaches back to Kant (Schiemann 2003; Stadler 2002).

I shall begin by characterizing the context distinction as employed by Reichenbach in "Experience and Prediction" to differentiate between epistemology and science (1). Following Thomas Nickles and Kevin T. Kelly, one can distinguish two meanings of the context distinction in Reichenbach's work. One meaning, which is primarily to be found in the earlier writings, conceives of scientific discoveries as potential objects of epistemological justification. The other meaning, typical for the later writings, removes scientific discoveries from the possible domain of epistemology. The genesis of both meanings, which demonstrates the complexity of the relationships obtaining between epistemology and science, can be made understandable by appealing to the historical context (2). Both meanings present Reichenbach with the task 
of establishing the autonomy of epistemology through the justification of induction. Finally, I shall expound this justification and address some of its elements of rationality characterizing philosophy of science (3).

Since the connection between the context distinction and induction is already made clear in his presentation in section 1 of "Experience and Prediction", and since Reichenbach provides here a relevant basis for subsequent reflections, I will go into some detail about this passage. Reichenbach speaks in section 1 of three tasks that are typical for epistemology in contrast to other disciplines: the "descriptive", the "critical" and the "advisory" task.

\section{The Descriptive Task}

The descriptive task consists in the "rational reconstruction" of scientific "thought processes". (By "science" Reichenbach means here and indeed for the most part natural science.) The concept of "rational reconstruction" is borrowed from Rudolf Carnap (Carnap 1928). It characterizes the normative task of epistemology: "to construct thinking processes in a way in which they ought to occur if they are to be ranged in a consistent system" (Reichenbach 1938, p. 5). Any logical connections missing between the "starting point and issue" of a real thought process are produced in such a way that the postulate of greatest possible correspondence is fulfilled (Reichenbach 1938, p. 5). This postulate has to presuppose that real scientific processes have something at least approximating a logical content. In order to characterize the relative difference between the reconstruction and its object, Reichenbach introduces his context distinction. He does justice to the relativity of this difference by defining rational reconstruction by analogy to scientific practice:

\footnotetext{
"If a more convenient determination of this concept of rational reconstruction is wanted, we might say that it corresponds to the form in which thinking processes are communicated to other persons instead of the form in which they are subjectively performed. [... The] well-known difference between the thinker's way of finding [...a] theorem and his way of presenting it before a public may illustrate the difference in question. I shall introduce the terms context of discovery and context of justification to mark this distinction. Then we have to say that epistemology is only occupied in constructing the context of justification. But even the way of presenting scientific theories is only an approximation to what we mean by the context of justification" (Reichenbach 1938, pp. 6-5-emphasis in original).
}

Thus, the distinction between contexts of discovery and justification is intended initially to mark a distinction within scientific practice. Scientific knowledge, according to Reichenbach, is often presented in a form different from that in which it was found. (Following Reichenbach, one could speak of an "inner-scientific" distinction of contexts.) The demarcation of the descriptive task of epistemology from science is a further step beyond this initial distinction. Epistemology differs from science in that its domain is limited to the context of justification, which exists to some extent also within science. 
Reichenbach does not offer any reason why scientists could not in principle reconstruct their theories themselves. He notes only two factors that prevent scientific presentations from meeting the demands of logic. First, there are "the traces of subjective motivation from which [... the scientific expositions] started" (Reichenbach 1938, p. 7). Secondly, "scientific language, being destined like the language of daily life for practical purposes, contains so many abbreviations and silently tolerated inexactitudes" (Reichenbach 1938, p. 7). But these explanations raise more questions than they answer. Why should "subjective motives" and "practical goals" lead to non-logical elements in the presentation of theories? Can these factors also influence logic and epistemology? What stands in the way of eliminating non-logical elements in the sciences-given that they are present-to a degree that satisfies logicians?

\section{Critical Task}

Until the initially vague demarcation is sharpened, there can be no foundation of the autonomy of epistemology. This is achieved in part by reference to the following two tasks. In its critical task, epistemology is no longer bound to the postulate of greatest possible correspondence. Reichenbach assumes now that the logical content of scientific thinking is so defective that a rational reconstruction cannot achieve a logically consistent structure. The "analysis of science" must therefore replace reconstruction.

We "replace actual thinking by such operations as are justifiable, that is, as can be demonstrated as valid" (Reichenbach 1938, p. 7).

But the analysis of science remains bound to the "starting point and issue" of real thought processes. Within this general condition the inductivist conception of science emerges, which Reichenbach was to develop further in the course of the book. This conception regards relations among data as the starting point and scientific theories-which reproduce and inductively generalize these relations by applying mathematical functions to them-as the issue of scientific thought processes. The goal of epistemology--as set out in chapter 5 of "Experience and Prediction"-is a formal demonstration of the validity of the inductive relations between data and theories. In pursuing this goal, the analysis of science can rely on structures that already exist--however incompletely formulated-in scientific presentations. Indeed, Reichenbach propounds the "thesis that all inferences occurring [in science] are of the inductive type" (Reichenbach 1938, pp. 370-371). The analysis of science endeavors to explicate the logical form of this inductive structure by resolving it into a structure of deductive relations, leaving the rule of induction as the only non-deductive relation (Reichenbach 1949a, p. 471). He understands the rule of induction-to choose one of his many formulations-as "the assumption that an event which occurred $n$ times will occur at all following times" (Reichenbach 1938, p. 341). I should like merely to note at this stage that the justification of this rule would exceed the scope of an 
epistemology characterized by the two tasks I have addresses thus far. As David Hume showed, the rule cannot be logically proven. Its justification-if at all possible demands that one abandon the field of logical analysis, which is the third task of epistemology licenses.

\section{Advisory Task}

In performing its advisory task, epistemology meets science as an independent discipline with positive suggestions. This is necessary, as Reichenbach sees it, because the analysis of science may be an indispensable tool for making correct decisions between different modes of presentation and different directions in which science might be developed.

With respect to different modes of presentation, Reichenbach only speaks of the choice between "equivalent conceptions" (Reichenbach 1938, p. 9), i.e., theories that he considers logically equivalent because they agree in all observable facts (Reichenbach 1938, p. 374; Reichenbach 1951, p. 180). One could mention at this point also the case of the non-equivalent theories Reichenbach discusses in chapter 5 , which differ in their prognoses and therefore present a problem of making a choice too (Reichenbach 1938, pp. 375-376). Unfortunately, Reichenbach offers no precise characterization of these two types of relationship between theories. It remains unclear just how broadly he construes the concept of logical equivalence. Strictly speaking, logical equivalence is only derived from empirical equivalence when all theoretical concepts are defined by observational concepts (Friedman 1983, p. 280; Klein 2000, p. 85). In any case, it is clear that for Reichenbach only logical analysis can determine whether theories are equivalent or non-equivalent. In the case of equivalent theories, science can be relied upon to choose between them on the basis of mere expediency. As for non-equivalent theories, on the other hand, Reichenbach believes that his theory of induction provides the framework in which a decision can be made (Reichenbach 1938, pp. 375-379). Hence, epistemology could exercise an important influence in the presentation of scientific theories. Apparently Reichenbach does not take into account (at least not in the context of "Experience and Prediction") the empirical underdetermination of scientific theories, as formulated by Pierre Duhem. Underdetermined theories may have the property of being logically incompatible and thus elude the competency of an analysis of science. If Reichenbach had taken this property into consideration, he could only have maintained the role of epistemology in examining and choosing between theories by abandoning his limitation to logical analysis and-like Neurath, for example-admitting values as a philosophical topic. $^{7}$

That this would not have been wholly out of the question is demonstrated by his ideas about "volitional bifurcations" which concern the direction in which science might be developed. Choices about the aims of research count as such bifurcations (Reichenbach 1938, pp. 10-11). Although Reichenbach does not mention it at this stage, justification of the rule of induction would also have to be included here, since it depends on the specific aim of predicting the future. Moreover, fundamental concepts 
of a philosophy of science-i.e., causality and probability-can be traced back to volitional bifurcations (Reichenbach 1938, p. 11).

Reichenbach does make the claim that the advisory task could be reduced to the critical task if epistemology is restricted to "constru[ing] a list of all possible decisions, each one accompanied by its entailed decisions [ . . and] leav[ing] the choice to our reader" (Reichenbach 1938,p. 14). But in the course of the book he does not justify his assertion that epistemology itself is free from volitional bifurcations. In subsequent chapters he makes decisions about the fundamental concepts of philosophy of science and logical presentation without displaying the alternatives neutrally to the reader. ${ }^{8}$

If one traces the relationship between epistemology and science step-by-step through the delineation of the three tasks, one arrives at a paradoxical conclusion. On the one hand, the distance between the two disciplines increases successively from the initial postulate of maximal correspondence to the merely formal relationship of inductive structure, and finally to the stage at which epistemology fulfils its advisory task as an independent discipline. But there is also a sense in which the distinction between the two disciplines becomes increasingly problematic. When Reichenbach asserts that the formal structure of scientific reasoning is essentially inductive and knowledge thereof is decisive in examining and choosing theories, the question presents itself to the reader: why should science have to yield the task of analyzing this structure to another discipline at all?

Epistemology, in Reichenbach's view, differs from science in that it is limited to the context of justification and focuses on its logical presentation. But the inductive structure of logical presentation refers to the question of discovery. Reichenbach conceives of "the aim of induction" as finding "the laws of nature in their most general form, including both statistical and so-called causal laws"'(Reichenbach 1938, p. 350). If real processes of discovery until now have not followed the inductive method, could epistemology develop an alternative logic of discovery? Reichenbach seems however to suspect that there are also rational elements already in real processes of discovery. In his critique of Karl Poppers's "Logik der Forschung" in 1935, he states that "the process of constructing scientific hypotheses ought to be rationalized" (Reichenbach 1935 b, p. 281). Can the thought processes involved in discovery be at least partially grasped through inductive logic? These questions show that the theory of induction plays a decisive role in the characterization of the context distinction as a criterion for distinguishing the two disciplines.

2.

Reichenbach gives no clear answer to these questions. In fact, his views on the context distinction were subject to vacillations over the years that cannot neatly be assigned to specific time periods. One can however tentatively distinguish two phases in which he emphasizes different aspects of its meaning (Nickles 1990, p. 158; Kelly 1991, pp. 137-139). In an early phase he places weight on the rationalization of processes of discovery as a matter for epistemology, whereas in a later phase he is inclined to 
doubt that this rationalization is possible and eliminates it from the epistemological context of justification.

\section{The Early Phase: Rationalizing Discovery}

The last two paragraphs of "Experience and Prediction" belong to the early phase. Here the distinction of contexts does not prevent scientific discoveries from following the inductive method too.

"If we were to analyze the discoveries of [... scientists], we would find that their way of proceeding corresponds in a surprisingly high degree to the rules of the principle of induction [...]. The mysticism of scientific discovery is nothing but a superstructure of images and wishes; the supporting structure below is determined by the inductive principle. [ . . It] seems to be a psychological law that discoveries need a kind of mythology $[, \ldots]$ that sometimes those men will be best in making inductions who believe they posses other guides" (Reichenbach 1938, p. 403) (Reichenbach uses the term "principle of induction" here and elsewhere synonymously with "rule of induction".)

The context distinction assumes the shape of a distinction formulated in Marxist terminology between super- and supporting structure. ${ }^{9}$ The inductive supporting structure is susceptible of justification, whereas the mythology of the superstructure-i.e., "instinctive presentiments" and "belief in a mystic harmony between nature and reason" (Reichenbach 1938, pp. 403-404), but also "belief in induction, belief in a uniformity of the world" (Reichenbach 1938, p. 403)-is not. These notions, which for whatever inexplicable reasons are necessary for the application of induction in the sciences, could only be left to psychology to investigate. Within the framework provided by this conception, the history of science-which Reichenbach does not address-would deal with the superstructure as well as the supporting structure (cf. Salmon 1970).

As much as these and other formulations in the last two paragraphs of "Experience and Prediction" seem to place Reichenbach in proximity to a "logic of discovery" (Nickles 1980; Curd 1980; Laudan 1980), a close reading reveals that he does not go beyond general statements like those in the passage quoted above. In none of the examples he mentions does he claim that natural scientists "find" theories by applying an inductive method. ${ }^{10}$ It always remains an open question how the scientists arrive at their theories. It may be that they are guided by inductive considerations, but as for this question, Reichenbach says merely: "we do not maintain anything" (Reichenbach 1938, p. 382). He does not question the distinction between supporting structure and superstructure.

At the same time, it stands firm in "Experience and Prediction" that theory generation in the sciences may in principle proceed inductively, and that the context of discovery belongs among the possible objects of an analysis of science. ${ }^{11}$ Against this background, Reichenbach must have been uncertain whether it might have been better to advise scientists to employ the inductive method in their pursuit of discovery instead of abandoning themselves to mythology. His ambivalent stance is reflected in the rhetoric with which he invests the distinction of contexts in the penultimate paragraph. On the one hand, he disparages scientists by suggesting that they 
1949b, p. 293). Though the relationship between discovery and justification in the sciences may be complex, the tasks of epistemology remain henceforth limited to the context of justification. Epistemology has no pretensions about reconstructing the context of discovery.

\section{The Historical Context of the Discussion of Induction}

Although I do not want to over-emphasize the vacillations in Reichenbach's conception of the context distinction, I would like to have a closer look at its historical contextincluding its establishment through the justification of induction. The vacillations can be attributed to uncertainties that are understandable in light of the considerable difficulties faced by the logical empiricists as they re-settled to the US in the 1930s.

According to Ronald N. Giere, philosophy in German in the opening decades of the twentieth century was shaped by a "Kantian framework", whereas the "philosophical climate" of the US was dominated by the traditions of Empiricism and Pragmatism (Giere 1999, p. 225). Giere invokes this difference to explain the fact that probability and induction, which had "not played a significant role" for the logical empiricists before their relocation, became "major topics in the philosophy of science." Indeed, although Reichenbach had occupied himself as early as 1916-in his dissertationwith the theory of probability, it was not until he left Berlin that he began actively publishing work on the induction problem. ${ }^{16}$ From that point on, induction was to remain in the foreground-not only in "Experience and Prediction" but also in the English edition of the "Theory of Probability."

In the US, induction was an ideal area for Reichenbach to establish himself with a contribution. ${ }^{17}$ With his justification of the rule of induction, he succeeded. He himself believed that he had no less than "finally arrived at a solution to the induction problem", which had stood "as the unsolved riddle before all empiricist philosophy since the time of Hume" (Letter of June 3, 1935 to Ernst von Aster, quoted in Kamlah 1994, p. 533). In "Experience and Prediction" and in the English edition of the "Theory of Probability", the justification of the rule of induction assumes central importance.

Reichenbach intended to show with the context distinction that the logical analysis of induction and the justification of induction he had proposed are among the tasks that belong exclusively within the province of epistemology. At the same time, only after justifying the rule of induction could Reichenbach demonstrate that logical analysis avails itself exclusively of justified laws and thereby establish the distinction between contexts of discovery and justification. Justification of the laws of deduction is unproblematic, since they "always lead to true sentences if the premises are true. [... But for] the rule of induction such a proof is not possible" (Reichenbach 1949a, p. 471). In the absence of a justification of the rule of induction, there can be no response to the Humean argument that one assumes the validity of induction out of habit. Induction would belong alongside the non-rational elements of discovery among the objects that can only be analyzed by psychology. Thus neither the earlier 
interpretation of the context distinction nor the later one can be maintained without a justification of the rule of induction.

3.

In order to distinguish Reichenbach's justification of the rule of induction from a "validation", Herbert Feigl characterized it as a "vindication". Rules are validated when they are derived from a fundamental principle. When this is impossible-as in the case of the rule of induction - their use can be vindicated by defending its appropriateness for a given purpose (Feigl 1950). I would like to add that a rule which has been justified in this manner can be regarded as rational in an instrumental sense, since the appropriateness of its application is established only as a means to a given goal. A more broadly construed concept of rationality could surely encompass the well-founded choice of goals. But this would not accurately represent Reichenbach's procedure, since he gives no reasons for his choice of the aim of the scientific method, namely "of predicting the future" (Reichenbach 1949a, p. 474, or Reichenbach 1938, pp. 349-350). Moreover, he does not address alternatives to this resolution-like Goethe's decision to limit his scientific research to the description of nature, or the atomistic program of explaining nature, to mention just two of the historically most significant examples-although such a discussion would be possible within the framework of the advisory task of epistemology (see part 2 above).

The decision in favor of prognosis determines Reichenbach's formulation of the rule of induction, i.e., "that an event which occurred $n$ times will occur at all following times" (Reichenbach 1938, p. 341; see above). He believes that a defense of induction can only succeed within the framework of his theory of probability. The core of his argumentation can however be understood independently of the specific probabilistic interpretation with which he invests it. It corresponds to the structure of Blaise Pascal's famous wager, according to which one must decide in favor of belief in the existence of God, since this is the only way one might-if God indeed exists-attain truth and salvation. ${ }^{18}$

Like Pascal, Reichenbach assumes two possible states of the world and two possible courses of action. For Reichenbach, the world can be either uniform or non-uniform. Insofar as he does not think it possible to know the actual state of the world, he shares Hume's scepticism. The possible courses of action-given independently of the state of the world-can be divided disjunctively into the inductive and the non-inductive. This scheme yields four possible states:

1. The application of the inductive method leads in the long run to certain success in the uniform world.

2. In the non-uniform world its successes are merely coincidental, thus its success is on the whole uncertain.

3. Uncertainty of prognostic success is also characteristic of the state of the nonuniform world when the inductive method is not employed, i.e., when either no methodology or non-inductive methods such as clairvoyance are used. 
4. But it in fact makes a difference in the uniform world which of these non-inductive variants one chooses. Only the absence of any methodology at all would in general be unsuccessful. The possible success of a non-inductive method, however, could only be assessed in comparison to the results of the inductive method. There can be no guarantee of prognostic success in the uniform world when induction is not employed. ${ }^{19}$

Given Reichenbach's suppositions, induction is the surest procedure for attaining successful prognoses - when success is possible. The first state is the only rational one. The vindication has a pragmatic character, since-and herein lies another resemblance to Pascal's wager-it does not defend belief in the success of actions but the rationality of a procedure for choosing actions. ${ }^{20}$ "Actions directed by the rule of induction are legitimate attempts at success; no form of belief is required for the proof" (Reichenbach 1949a, p. 481). Hence, belief in the success of induction is just as mythical in nature as belief in the success of non-inductive procedures in the sciences.

The validity of Reichenbach's vindication remains controversial. ${ }^{21}$ As I have already stated, I do not want to enter into a discussion of the criticism. Rather, I would like simply to concede the argument-with one qualification-in order to show how a claim to rationality can be utilized in establishing the autonomy of a discipline. The qualification concerns Reichenbach's exclusive identification of the goal of science with prognosis. Although one may concede the plausibility of his argument that the choice of induction in pursuance of this goal is rational, one ought not forget that other goals might be incompatible with induction and other means necessary to achieve them. To stick with the aforementioned examples, Goethe's research of nature led him to a critique of induction, and the atomistic program of explaining nature led to the assumption of non-inductive hypotheses.

I would like to emphasize three of the things that can be learned from Reichenbach's pragmatic justification of induction and its relation to the context distinction. First, Reichenbach is right to emphasize the tremendous significance of induction in the natural sciences. Since the Aristotelian beginnings of science and of theoretical reflection about the methods of science, induction has played a key role in both areas. The inductive procedure is among the methods of contemporary science the application of which transcend epochal and disciplinary boundaries. The focus on such non-local structural patterns in the development of science is more characteristic of the philosophy of science than of the history of science (Radder 1996). Induction being among these structural patterns (others would be mathematization and technization), the context of justification being the name of an appropriate domain for theoretical reflection about these patterns, and the context of discovery being the name of an appropriate domain for the presentation of their historical reality, one may say that the context distinction reflects a plausible relation between philosophy and history of science.

Secondly, the discussion of induction is not only thematically, but also methodologically, exemplary of specific characteristics of philosophy of science. This is made 
clear by the argumentative character of the vindication of induction, upon which Reichenbach bases epistemology's claim to justification. According to Reichenbach "the justification of a theory in terms of observational data is the subject of the theory of induction," which - apart from the rule of induction -avails itself exclusively of deductive laws (Reichenbach 1951, p. 231). This claim of justification holds for every application of the theory of induction, whether it be with approximately logical content as in the sciences, or with exclusively logical form as in Reichenbach's epistemology. But the vindication - in contrast to its object, namely induction-is categorically distinct from the scientific justification, since it proceeds not empirically but argumentatively. Thus the vindication of induction establishes the autonomy of epistemology even if an epistemological analysis of science cannot be distinguished sharply from the inductive procedure of the sciences, as in the earlier of the aforementioned phases of the context distinction. Argumentative justifications are typical of philosophy and still constitute a criterion for distinguishing philosophy from science studies.

Thirdly, in addition to distinguishing philosophy form other disciplines, the vindication yields an inner-philosophical distinction as well. Its object differs for example from all non-inductive procedures, such as Popper's deductive falsificationism. Its pragmatic character distinguishes it from Carnap's attempt to meet Hume's challenge with a new concept of theoretical rationality (Schramm 1993, pp. 548-553).

\section{CONCLUDING REMARKS}

I set out to look for arguments to account for the relevance of Reichenbach's distinction between a context of discovery and a context of justification upon the establishment of the autonomy of philosophy of science (which he calls epistemology). The autonomy of this discipline is problematic for Reichenbach because of its close relationship to the practice and theory of science. Justification is conceived of in his writings as essentially inductive and as a topic for the sciences and epistemology. The epistemological justification differs from the scientific one only in that it is limited to logical form. It remains unclear why the sciences should not also be competent to carry out a purely logical analysis of their inductive methods of inference.

According to Reichenbach, it is more typical for the sciences than for epistemology to aim for discoveries. In his writings it remains an open question to what extent the processes of scientific discovery are inductive and hence a potential object of inquiry within the context of (scientific or epistemological) justification. In part, he seems not to want to exclude the possibility of future processes of discovery employing a strictly inductive logic, which would then dissolve the context distinction. But as for discoveries made up to the present, he assumes for the most part that they arise from circumstances as yet not uniformly characterized. Induction, on the other hand, is for Reichenbach a method generally characteristic of the sciences and of the justification of theories.

In Reichenbach's view, epistemology stands in danger of being dissolved into the sciences. But his context distinction is no merely verbal, last-ditch attempt at distinguishing epistemology. Reichenbach characterizes epistemology by appealing to 
the fact that it thematizes general characteristics of science. Although philosophy of science has long since stopped limiting itself to the logical analysis of scientific methods, this is still an aspect-alongside its focus on contemporary problemswhich distinguishes it from most research in the history of science. Reichenbach's justification of induction demonstrates paradigmatically how philosophy employs its own method-essentially argumentative in nature-outside the domain in which it seeks to justify the knowledge produced in other disciplines. This vindication belongs alongside Pascal's wager in the tradition of pragmatic arguments. Analyzing it reveals that Reichenbach's one-sided focus on the prognostic goals of science and on the inductive method does not entail the exclusion of discoveries from the context of justification. Rather, it impugns the claim to validity of non-inductive procedures taken to be pre-requisites to the formulation of theories.

If one drops the claim to exclusivity with which Reichenbach invests his vindication, one can learn from his procedure that the foundation of the autonomy of a discipline can emerge from a justification that ascribes rationality to the methods of that discipline. Reichenbach was right in viewing methodological rationality as dependant upon the goals attributed to a given domain of research, yet he overlooked the plurality of such goals.

\section{ACKNOWLEDGMENTS}

I am grateful to the participants of the Workshops "Revisiting Discovery and Justification" at the Max-Planck-Institut für Wissenschaftsgeschichte for their helpful comments. Thanks also to Professor Kamlah for his stimulating suggestions, and to John Michael for his translation.

\section{NOTES}

1. The literature concerning the debate between philosophy and history of science is extensive. For an overview see Laudan 1990; Hull et al. (eds.), 1992; Nickles 1995. For more recent publications, see for example Radder 1997; Pinnick and Gale 2000; Burian and Steinle 2002.

2. Reichenbach's motivations in formulating the context distinction are discussed in Zittlau 1981, 44; Nickles 2002; Stadler 2002; Howard 2004; Howard, this volume.

3. Concerning the reception of the context distinction generally, i.e. insofar as it cannot be attributed exclusively to Reichenbach, see Hoyningen-Huene 1987; for the reception of Reichenbach's version of it Schiemann 2003, p. 237. In connection with the treatment of Reichenbach's theory of induction, there is some discussion of the context distinction in Salmon 1991; Kelly 1991. As for Reichenbach's theory of induction, see also Clendinnen 1979; Schramm 1993.

4. Concerning the debate about Reichenbach's justification of the theory of induction, see Clendinnen 1979; Schramm 1993; Kamlah 1994, 545-549; Gerner 1997, 165 et seq. More recently Piller 1987; Schurz 1988.

5. This version corresponds most nearly to the fourth version characterized by Hoyningen-Huene (this volume), although Reichenbach counts the natural sciences among those empirical disciplines from which epistemology is distinct.

6. In another passage, Reichenbach explains "the division of labour between the physicist and the philosopher" by referring to the "limitation of human capacities": "It appears to be practically impossible that the man who is looking for new physical laws should also concentrate on the 
analysis of his method". Moreover, there is a difference in the mentalities of the two groups of people: "The discovery of general relations [...] requires a mentality different from that of the philosopher, whose methods are analytic and critical rather than predictive" (Reichenbach 1949b, p. 292).

7. Cf. Howard's and Richardson's discussions in this volume.

8. The definition of probability based on frequency is, for example, by no means the only alternative; and the reduction of causality to inductive relations of probability is also controversial.

9. Maria Reichenbach and Hermann Vetter translate "super- and supporting structure" with "Unterund Überbau" (Reichenbach 1983, p. 253).

10. Referring to Galileo he constrains himself to the formulation "he found that the quantities measured fit into the formula $s=g t^{2} / 2$, and inferred, by means of the inductive principle, that the same law holds for similar cases" (Reichenbach 1938, p. 371). Of Darwin he only writes: when "Darwin formulated [his] theory, it was based on facts" (Reichenbach 1938, p. 390). And as for Einstein, he remarks merely that he "saw-as his predecessors had not seen-that the known facts indicate such a theory; i.e., that an inductive expansion of known facts leads to the new theory" (Reichenbach 1938, p. 382).

11. Reichenbach does not consistently assert the rationalizability of discoveries throughout his early writings: "the procedure of discovery is however hardly rationalizable" (Reichenbach 1935a, p. 172).

12. On other occasions Reichenbach states more explicitly that he does not even believe scientists who claim to have arrived at their theories by non-inductive means: (Reichenbach 1935b, pp. 281-282).

13. Some interpreters claim that Reichenbach does not justify the distinction in "Experience and Prediction" (Giere 1999, p. 228; Kelly 1991, pp. 137-140). Since later discussions of the distinction do not repeat the justification, Kelly speaks of a "dogma" (Kelly 1991, p. 139). This characterization is inaccurate, though, considering that Reichenbach attempted to justify the distinction not only directly upon introducing it but also in the context of his work.

14. In Reichenbach 1949b, the "challenge of developing rules for a logic of discovery" is not sharply distinguished from logical analysis: the "philosopher of science is not much interested in the thought processes which lead to scientific discoveries" (Reichenbach 1949b, p. 292).

15. This meaning matches up with Hoyningen-Huene's Version 1 (this volume).

16. He made the first announcement of his "illumination of the induction problem" in a letter to Moritz Schlick dated February 22, 1933 (Kamlah 1994, p. 546). There is an anecdote that Reichenbach proclaimed as the Nazis closed the Berlin University: "Now I understand the induction problem" (Giere 1999, p. 226).

17. Giere 1996 assumes that Reichenbach applies the context distinction in order to establish induction as a topic for Logical Empiricism. However, Howard 2004b, p. 23, points out that the context distinction received critically among American Pragmatists.

18. Pascal 1984, Fragm. 233. On the structure of Pascal's wager, cf. Hacking 1975, pp. 63-72; Jordan 1994. On the similarity between Reichenbach's pragmatic justification and Pascal's wager see Creed 1939; Salmon 1991; Gerner 1997; Schramm 1999; Kamlah 1977, p. 479 draws attention to a difference.

19. Reichenbach 1933; Hertz 1936; Reichenbach 1936; Reichenbach 1949a, pp. 469 -482; Reichenbach 1938, pp. 348-357; Salmon 1991, p. 100; see also literature of Footnote 4.

20. In 1939, Reichenbach referred explicitly to the close systematic relationship between the pragmatic character of his justification of induction and the work of American pragmatists Dewey and Peirce on the induction problem (Reichenbach 1939, pp. 187-190). It cannot be ruled out that he may have been chosen to work on the issue of induction, and also proposed a pragmatic justification of the rule of induction, with a mind to improving his chances for a professorship in the US. In doing so, Reichenbach distanced himself from the typically Kantian transcendental justification, which he himself developed in his dissertation on the related problem of probability. The pragmatic and the transcendental justifications share only the general demand for "a necessary 
condition" of knowledge in common (Reichenbach 1936. cf. Kamlah 1977, pp. 476-480; Kamlah 1989, pp. 443-447; Richardson, this volume).

21. Cf. Footnote 4.

\section{REFERENCES}

Carnap, R. (1928), Der logische Aufbau der Welt (Berlin: Weltkreis).

Clendinnen, J. F. (1979), "Inference, Practice and Theory", in Salmon (ed.), pp. 85-128.

Creed, I. P. (1940), "The Justification of the Habit of Induction" The Journal of Philosophy 37: $85-97$.

Curd, M. (1980), "The Logic of Discovery: An Analysis of Three Approaches", in T. Nickles (ed.), Scientific discovery, Logic and Rationality (Dordrecht: Reidel), pp. 201-219.

Feigl, H. (1950), "De Principiis Non Disputandum ...?", in M. Black (ed.), Philosophical Analysis (Ithaca), pp. 119-56.

Friedman, M. (1983), Foundation of Space-Time Theories (Princeton: Princeton University Press).

Gerner, K. (1997), Hans Reichenbach-sein Leben und Wirken, eine wissenschaftliche Biographie (Osnabrück: Phoebe-Autorenpress).

Giere, R. N. (1999), Science without Laws (Chicago: University of Chicago Press).

Hacking, I. (1968), "One Problem about Induction", in L. Lakatos (ed.), The Problem of Inductic Logic (Amsterdam : North-Holland Publishing Company), pp. 44-59.

Hacking, I. (1975), The Emergence of Probability (Cambridge: Cambridge University Press).

Haller, R. und F. Stadler (eds.), (1993), Wien-Berlin-Prag: Der Aufstieg der wissenschaftichen Philosophie. Zentenarien RudolfCarnap-Hans Reichenbach-Edgar Zilsel (Wien: Hölder-PichlerTempsky).

Hertz, P. (1936), "Kritische Bemerkungen zu Reichenbachs Behandlung des Humeschen Problems", Erkenntnis 6: 25-31

Howard, D. (2004), "Two Left Turns Make a Right: On the Curious Political Career of North American Philosophy of Science at Mid-Century", manuscript.

Hoyningen-Huene, P. (1987), "Context of Discovery and Context of Justification", Studies in History and Philosophy of Science 18: 501-515.

Hull, D. et al. (eds.), (1992), "Symposium: What has the History of Science to say to the Philosophy of Science?", in D. Hull et al. (eds.), (1992): Proceedings of the 1992 Biennial Meeting of the Philosophy of Science Association, pp. 467-496.

Jordan, J. (ed.) (1994), Gambling on God. Essays on Pascal's Wager (Lanham: Rowman \& Littlefield).

Kamlah, A. (1977), "Erläuterungen, Bemerkungen und Verweise zum Vortrag 'Rationalismus und Empirismus' und zum Buch 'Der Aufstieg der wissenschaftlichen Philosophie”', in Reichenbach 19711999 Vol. 1, pp. 466-480.

Kamlah, A. (1985), "The Neokantian Origin of Hans Reichenbach's Principle of Induction", in N. Rescher (ed.), The Heritage of Logical Positivism (Lanham: University Press of America).

Kamlah, A. (1989), "Erläuterungen, Bemerkungen und Verweise zu den Schriften dieses Bandes", in Reichenbach 1971-1999 Vol. 5, pp. 371-454.

Kamlah, A. (1994), "Erläuterungen zu: H. Reichenbach, Wahrscheinlichkeitslehre", in Reichenbach 1971-1999 Vol. 7, pp. 519-549.

Kamlah, A. (1998), "Hans Reichenbach", in E. Craig (ed.), Routledge Encyclopedia of Philosophy (London/New York: Routledge).

Kelly, K. T. (1991), "Reichenbach, Induction, and Discovery", Erkenntnis 35: 123-149.

Klein, C. (2000), Konventionalismus und Realismus. Zur Erkenntnistheoretischen Relevanz der empirischen Unterbestimmtheit von Theorien (Paderborn: Mentis-Verlag).

Laudan, L. (1980), “Why Was the Logic of Discovery Abandoned?", in Nickles (ed.), pp. 173-183.

Laudan, L. (1990), "The History of Science and the Philosophy of Science", in R. Olby (ed.), Companion to the History of Science (London/New York: Routledge), pp. 47-59. 
Nickles, T. (1980), "Introductory Essay: Scientific Discovery and the Future of Philosophy of Science", in Nickles (ed.), pp. 1-59.

Nickles, T. (1990), "Discovery", in R. Olby (ed.), Companion to the History of Science (London New York: Routledge), pp. 148-165.

Nickles, T. (1995), "Philosophy of Science and History of Science", in Osiris: A Research Journal Devoted to the History of Science and its Cultural Influences Vol. 10, pp. 139-163.

Nickles, T. (2002), "The Discovery-Justification-Distinction and Professional Philosopy of Science", in Schickore and Steinle (eds.), pp. 67-78.

Pascal, B. (1984), Gedanken. Üb., hg. und eingel. von E. Wasmuth (Stuttgart: Reclam).

Piller, C. (1987), "Das Vindizierungsargument-seine Wichtigkeit, seine Wirksamkeit seine Widerlegung", Grazer Philosophische Schriften 29: 35-58.

Pinnick, C., and G. Gale (2000), "Philosophy of Science and History of Sciene: A troubling Interaction", Journal for General Philosophy of Science 31: 109-125.

Radder, H. (1996), In and About the World. Philosophical Studies of Science and Technology (New York: State University of New York Press).

Radder, H. (1997), "Philosophy and History of Science: Beyond the Kuhnian Paradigm", Studies in History and Philosophy of Science 28: 633-655.

Reichenbach, H. (1929), "Ziele und Wege der physikalischen Erkenntnis", in H. Geiger und K. Scheel (eds.), Handbuch der Physik. Vol. 4. (Berlin: Springer).

Reichenbach, H. (1933), "Die logischen Grundlagen des Wahrscheinlichkeitsbegriffes", Erkenntnis 3: 401-425.

Reichenbach, H. (1935a), "Zur Induktionsmaschine", Erkenntnis 5: 172-173.

Reichenbach, H. (1935b), "Über Induktion und Wahrscheinlichkeit. Bemerkungen zu Karl Poppers 'Logik der Forschung"', Erkenntnis 5: 267-284.

Reichenbach, H. (1935c), Wahrscheinlichkeitslehre (Leiden: A.W. Sijthoff's Uitgeversmaatschappij).

Reichenbach, H. (1936), "Warum ist die Anwendung der Induktionsregel für uns notwendige Bedingung von Voraussagen?", Erkenntnis 6: 32-40.

Reichenbach, H. (1938), Experience and Prediction. An Analysis of the Foundation and Structure of Knowledge (Chicago/Illinois: University of Chicago Press).

Reichenbach, H. (1939), "Dewey's Theory of Science", in P. Schilpp (ed.), The Philosophy of John Dewey (Evanston: North Western University).

Reichenbach, H. (1944), "Philosophische Grundlagen der Quantenmechanik", in Reichenbach 19711999 Vol. 5.

Reichenbach, H. (1947), "Grundzüge der symbolischen Logik", in Reichenbach 1971-1999 Vol. 6.

Reichenbach, H. (1949a), The Theory of Probability. An Inquiry into the Logical and Mathematical Foundation of the Calculus of Probability (Berkeley/Los Angeles: University of California Press).

Reichenbach, H. (1949b), "The Philosophical Significance of the Theory of Relativity", in P. A. Schilpp (ed.), Albert Einstein: Philosopher Scientist (Evanston: The Library of Living Philosophers, pp. 287-311).

Reichenbach, H. (1951), The Rise of Scientific Philosophy (Berkeley etc.: University of California Press). Reichenbach, H. (1968), Der Aufstieg der wissenschaftlichen Philosophie (Braunschweig: Vieweg).

Reichenbach, H. (1971-1999), Gesammelte Werke in 9 Bänden (Braunschweig/Wiesbaden: Vieweg).

Reichenbach, H. (1983), Erfahrung und Prognose. Eine Analyse der Grundlagen und der Struktur der Erkenntnis, in Reichenbach 1971-1999 Vol. 4.

Reichenbach, H. (1994), "Wahrscheinlichkeitslehre". 2. Auflage auf Grundlage der erweiterten amerikanischen Ausgabe bearbeitet und herausgegeben von G. Link. Mit Erläuterungen von A. Kamlah, in Reichenbach 1971-1999 Vol. 7.

Salmon, W. C. (1968), "The Justification of Inductive Rules of Inference", in L. Lakatos (ed.), The Problem of Inductic Logic (Amsterdam: North-Holland Publishing Company), pp. 24-43.

Salmon, W. C. (1970), "Baye's Theorem and the History of Science", in H. Stuewer (ed.) Historical and Philosophical Perspectives of Science (Minnesota: University of Minnesota Press). pp. 68-86.

Salmon, W. C. (1991), "Hans Reichenbach's Vindication of Induction”, Erkenntnis 35: 99-122. 
Salmon, W. C. (ed.), (1979), Hans Reichenbach: Logical Empiricist (Dordrecht etc.: Reidel).

Schickore, J. and F. Steinle (eds.), (2002), Revisiting Discovery and Justification. Preprint 211. MaxPlanck-Institut für Wissenschaftsgeschichte (Berlin).

Schiemann, G. (2003), "Criticizing a difference of contexts. On Reichenbach's Distinction between "Context of Discovery" and "Context of Justification"', in F. Stadler (ed.), The Vienna Circle and Logical Empiricism. Re-evaluation and Future Perspectives (Dordrecht), pp. 237-252.

Schramm, A. (1993), "Zwei Theorien der Induktion--Reichenbach und Carnap", in Haller und Stadler (eds.), pp. 538-554.

Schurz, G. (1988), "Das Vindizierungsargument funktioniert doch: Eine Erwidenung auf Christian Piller", Grazer Philosophische Studien 32: 187-195.

Stadler, F. (2002), "Challenging the Dogma of the Ahistorical Philosophy of Science: The Case of Relativism", in Schickore and Steinle (eds.), pp. 27-40.

Steinle, F., and R. M. Burian (2002), "Introduction: History of Science and Philosophy of Science", Perspectives and Science 10: 391-397.

Zittlau, D. (1981), Die Philosophie von Hans Reichenbach (München: Minerva-Publikation). 


\title{
Revisiting Discovery and Justification
}

\author{
Historical and philosophical perspectives \\ on the context distinction
}

\author{
Edited by \\ JUTTA SCHICKORE \\ Indiana University, Bloomingdales, \\ IN, U.S.A. \\ and \\ FRIEDRICH STEINLE \\ Bergische Universität Wuppertal, \\ Germany
}

\section{包 Springer}

